\title{
Corrosion and High Temperature Oxidation Behavior of Structural Steels Coated with Aluminum Alloys
}

\author{
Kadri Vefa Ezirmik ${ }^{*},{ }_{\text {, Furkan Kalan }}^{2}$ \\ ${ }^{1}$ Ataturk University, Department of Metallurgical and Materials Engineering, Erzurum, Turkey \\ ${ }^{2}$ Ataturk University, Graduate School of Natural and Applied Sciences, Erzurum, Turkey
}

\section{Keywords}

\section{Hot dip,}

Aluminum coatings,

Corrosion,

High temperature oxidation,

AA1050,

AA2024,

AA5083.

\begin{abstract}
Structural steels are among the most widely used materials in today's industry. Various surface coating processes are used to protect structural steels from corrosion in atmospheric or aggressive environments. The most commonly used method is the galvanizing process based on forming zinc coating on the steel surface by using the hot dip method. Zinc coatings are insufficient to protect against corrosion, especially in chlorinated environments. Aluminum and its alloys stand out as an alternative material group to zinc in chlorinated environments. In this study, aluminum and aluminum alloy coatings, which are thought to be an alternative to zinc coating, were coated on the structural steel surface using the hot dip method. To examine how different aluminum alloys affect the corrosion and hightemperature oxidation properties of steels, nearly pure AA1050, high Cu content AA2024, and high Mg content AA5083 alloys were coated on structural steels. The coating process was carried out by dipping the structural steels into molten aluminum baths kept at a constant temperature of $700^{\circ} \mathrm{C}$ for 1,3 , and 5 minutes. The optimum adhesion and surface properties were obtained from dipping time for 3 minutes. The properties of coatings and intermetallic structures formed at the coating-steel interface were examined using an optical microscope, X-ray Diffractometer (XRD), Scanning Electron Microscope (SEM), and Energy Scattering Spectroscopy (EDS) systems. To examine the high-temperature oxidation properties of the coatings, the coated samples were oxidized for 24 hours at $750^{\circ} \mathrm{C}$ under open-air conditions, and the changes in weight were investigated. Immersion corrosion tests were performed in $3.5 \% \mathrm{NaCl}$ solution, and corrosion losses and degradation patterns were investigated. As a result of the studies, it has been determined that the $\mathrm{Al}$ coatings produced by the hot dip process significantly increase the oxidation and corrosion resistance of the structural steels.
\end{abstract}

\section{Introduction}

Since the surfaces of structural steels have a thermodynamically unstable structure, they generally want to return to their thermodynamically more stable oxide forms. This makes it inevitable for structural steel to corrode in many aggressive environments [1] To eliminate the corrosion problems, it is necessary to use more durable materials instead of steel, protect the steel surface with corrosion protection systems, or improve the surface properties of steel. Surface modification techniques or corrosion protection systems are much more economical than using materials with high corrosion resistance, such as stainless steel. For this purpose, materials with better corrosion resistance can be deposited on the structural steel surface. Preferred materials are generally metals that are electrochemically more active than iron, such as zinc, aluminum.

While these elements act as anodes, they protect the base material ( $\mathrm{Fe}$ ) cathodically [1]. Zinc coatings (galvanizing) are widely used on structural steel surfaces due to their low cost and superior sacrificial anode effect. Recently, there has been a need to find some alternatives to galvanized steels due to the limited mineral resources of zinc metal and fluctuations in its price [2]. Besides, the zinc coatings degrade rapidly, especially in chloride ( $\left.\mathrm{Cl}^{-}\right)$containing environments, causing material loss and environmental pollution. Some negative properties of galvanizing led to the search for alternative coating materials.

Aluminum is another coating material used in the surfaces of structural steel. Aluminum is one of the most widely used non-ferrous metals due to its low cost and unique properties. Pure aluminum has low tensile strength but can exhibit good mechanical properties with the addition of some alloying elements. Aluminum alloys play a critical role in the aviation, transportation, and building industries, especially as a result of their specific strength. Aluminum reacts naturally with the oxygen in the atmosphere and forms a thin protective oxide layer defined as $\mathrm{Al}_{2} \mathrm{O}_{3}$. This oxide layer stabilizes the surface and prevents further reaction of the metal with the environment [3].

Aluminum-coated steels have been widely used in vehicles, bridges, highway structures, pressure vessels, and many other places since their entry into the industry $[4,5]$. There are many methods for coating steel with aluminum. Some of these are arc/plasma spray coating, cladding, electrolytic coating, and hot dip coating. Hot dip aluminizing is applied to steels where heat and oxidation resistance are the primary requirements. At the same time, considering environmental protection, affordability, and suitability for mass production, and superior corrosion resistance, hot-dip aluminum coating is an efficient and convenient method [6-11]. Different intermetallic phases are formed between the steel and aluminum layers due to the aluminum coating process by hot dipping on the steel surface. These phases generally have a very hard, thick, and brittle structure.

In this study, aluminum alloy coatings were applied by the hot-dip method on low carbon structural steels to improve corrosion resistance and high-temperature oxidation resistance. AA1050, AA2024, and AA5083 series aluminum alloys are used as coating materials. The coating process was carried out in a liquid aluminum bath fixed at $700^{\circ} \mathrm{C}$ and at different immersion times $(1,3$, and 5 
minutes). The corrosion and oxidation behavior of steel surfaces coated with different $\mathrm{Al}$ alloys were investigated.

\section{Experimental}

\subsection{Substrate and coating materials}

Low carbon structural steel St37 was used as the substrate material. The chemical composition of the steel is given in Table 1.

Aluminum alloys were purchased from ETI Aluminum Corp. as ingots and cut to fit into the crucible. AA1050, AA2024, and AA5083 series aluminum alloys are used as coating materials. Chemical compositions of aluminum alloys are given in Table 2.

Table 1. Chemical composition of St37 steel (wt.\%)

\begin{tabular}{cccccc}
\hline $\mathrm{C}$ & $\mathrm{Mn}$ & $\mathrm{P}$ & $\mathrm{S}$ & $\mathrm{N}$ & $\mathrm{Fe}$ \\
\hline 0.14 & 1.13 & 0.025 & 0.032 & 0.009 & $>98$ \\
\hline
\end{tabular}

Table 2. Chemical composition of used Al alloys [12]

\begin{tabular}{llcccccccc}
\hline & $\mathrm{Al}$ & $\mathrm{Fe}$ & $\mathrm{Si}$ & $\mathrm{Cu}$ & $\mathrm{Mn}$ & $\mathrm{Mg}$ & $\mathrm{Zn}$ & $\mathrm{Ti}$ & $\mathrm{Cr}$ \\
\hline AA1050 & 99.5 & 0.40 & 0.25 & 0.04 & - & - & 0.05 & 0.04 & - \\
AA2024 & $>90$ & 0.50 & 0.50 & 4.35 & 0.60 & 1.10 & 0.25 & 0.15 & 0.10 \\
AA5083 & $>90$ & 0.40 & 0.40 & 0.10 & 1.20 & $\mathbf{4 . 5 0}$ & 0.25 & 0.25 & 0.15 \\
\hline
\end{tabular}

\subsection{Surface Preparation Before the Coating Process}

The chemical surface cleaning process has not been applied to the steel substrates before the coating process. The rusts and oxides on the surface were removed by using only mechanical cleaning processes. The surfaces of the steel samples were cleaned with a motorized steel wire brush. Holes of $2 \mathrm{~mm}$ diameter were drilled on one end of the flat specimens, and the hanging wires were fixed in the holes.

\subsection{Hot dip process and characterization}

An electric melting furnace was used to melt aluminum samples. The furnace's crucible capacity is $1 \mathrm{~kg}$, and it can reach a maximum temperature of $1100^{\circ} \mathrm{C}$. Graphite crucibles are used to melt aluminum samples. The furnace is fixed at a temperature of $700^{\circ} \mathrm{C}$, where the dipping process will occur.

Slag removal from the surface of the molten bath was carried out before and after the dipping process. Immediately after cleaning the oxide films on their surfaces, the steel samples were immersed in an aluminum bath at $700^{\circ} \mathrm{C}$. Immersed samples for planned periods were kept in water for a few seconds to cool them immediately after taking them out of the bath. It was then left to cool at room temperature. All these procedures were repeated multiple times for each sample. Some coated samples with AA1050, AA2024, and AA5083 are shown in Fig.1.

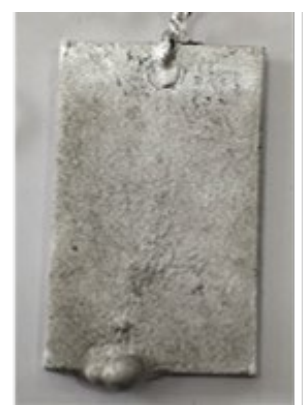

AA1050

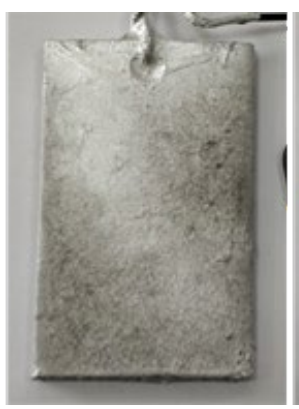

AA2024

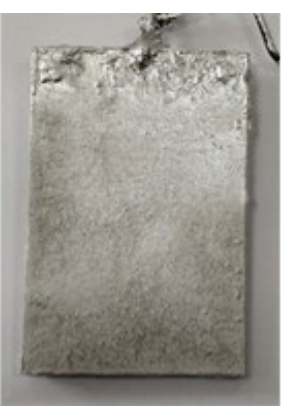

AA5083
Figure 1. Structural steels coated with different aluminum alloys
An optical microscope, Nikon LV 150, was used to take a crosssectional investigation and examine the changes in the samples' internal structure.

After the coating process, XRD analysis of the samples was carried out with Rigaku-2200D / Max X-Ray Diffractometer, which has a wavelength of $\mathrm{Cu}-\mathrm{Ka}$ radiation $\lambda=0.15404 \mathrm{~nm}$. Measurement values were obtained at a scanning range of $10-90^{\circ}$ at a scanning rate of 2 degrees/minute and $0.1^{\circ}$ steps. XRD results were analyzed in PANalytical X'Pert HighScore software using standard JCPDS (Joint Committee on Powder Diffraction Standards) data.

\subsection{Corrosion and oxidation tests}

The uncoated and aluminum coated samples were subjected to a corrosion test by immersion in $3.5 \% \mathrm{NaCl}$ solution for seven days. After the corrosion test, the samples were rinsed in distilled water, then kept in $70 \%$ nitric acid solution by weight for 2 minutes to remove the corrosion products on the surface and washed with distilled water. In this way, the weight changes of the samples in corrosive environments were examined. After the corrosion test, the cross-sectional images of the samples were examined.

The steel coated with AA1050, AA2024, AA5083, and uncoated steel samples were placed in the furnace heated to $750^{\circ} \mathrm{C}$. The oxidation process was carried out at a constant temperature for five different durations: $1 \mathrm{~h}, 2 \mathrm{~h}, 4 \mathrm{~h}, 6 \mathrm{~h}$, and $24 \mathrm{~h}$. The changes in weight of the oxidized samples in each interval were measured.

Surface morphologies of the coatings were examined using Zeiss Sigma 300 model SEM device. Images were taken from the coated surfaces and the intermetallic layer formed at the interface. To investigate the chemical composition of the samples, the EDAX Element EDS system, which is connected to the SEM device, was used.

\section{Results}

The cross-sectional images of AA1050 AA2024 and AA5083 coatings made on ST 37 substrates are given in Figure 2. It is observed that intermetallic phases are formed between the base material and the coating in the cross-sections, as stated in the literature [2]

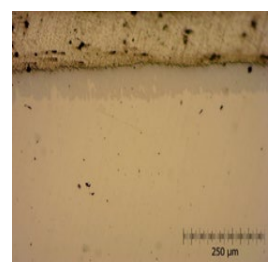

AA1050

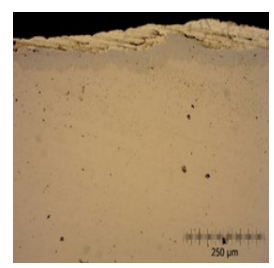

AA2024

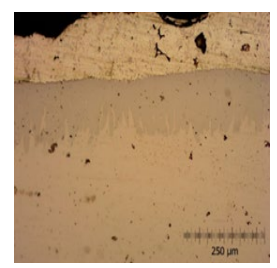

AA5083
Figure 2. Cross sectional images of coated samples

\subsection{XRD and EDS analysis}

An example of the XRD analysis results from coated steels and pure AA5083 aluminum is given in figure 3. It was determined by JCPDS 11179 card that the peaks formed belong to elemental aluminum. The changes in peak intensities and reflection angles are due to the aluminum alloys having different chemical compositions. The XRD analyzes of steel samples coated with different aluminum alloys were examined. There was no significant difference between the XRD peaks from the coating surface and the pure aluminum alloys. This shows that the aluminum alloys are successfully coated on St 37 steel surface without any phase change. 


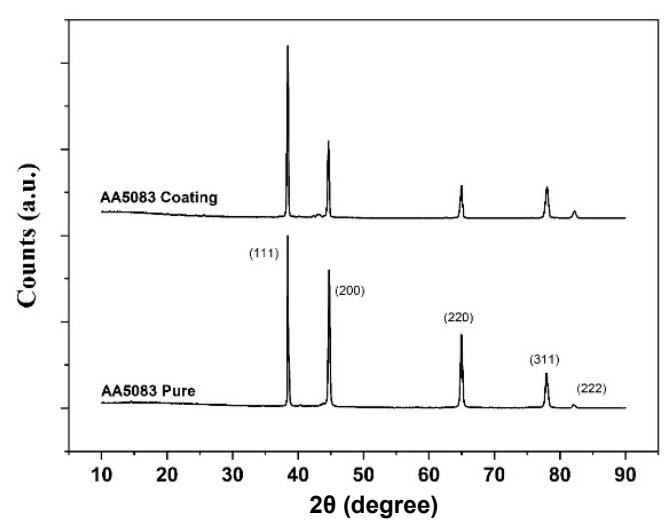

Figure 3. XRD graphs from AA5083 coated sample and pure AA5083

The Al percentage of the intermetallic layer in the AA5083 coatings (in table 3.), approximately $72 \%$, indicates that the $\mathrm{Fe}_{2} \mathrm{Al}_{5}$ composition is a predominantly formed phase in the intermetallic structure. A similar structure is observed from AA1050 coated samples. The intermetallic structure on the steel interface coated with AA2024 is prominent in the $\mathrm{FeAl}_{3}$ composition.

Table 3. EDS analysis of interlayer (atomic percentage)

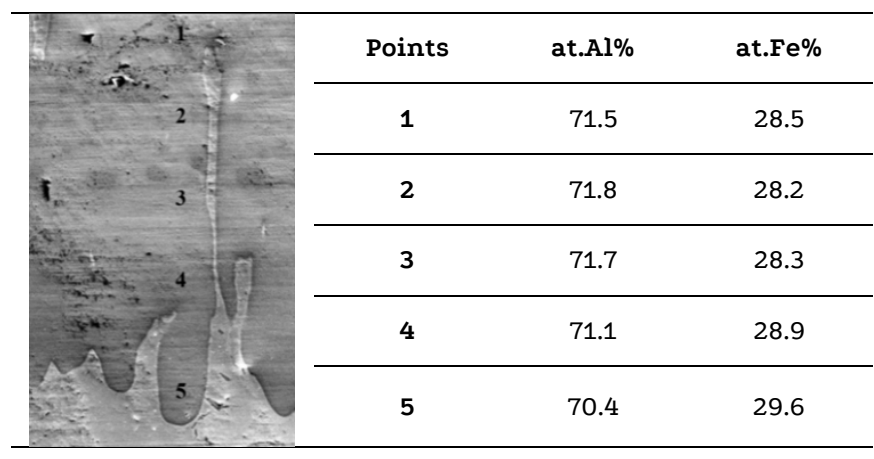

\subsection{Corrosion test results}

Table 4 represents the weight changes of samples immersed in 3.5\% $\mathrm{NaCl}$ solution after 8 days. When Table 4 is examined, the weight changes of structural steels coated with AA are much less than those of non-coated steels. This situation can be explained by the natural $\mathrm{Al}_{2} \mathrm{O}_{3}$ layer formed on the surface of aluminum, protecting the structural steel from corrosion [13].

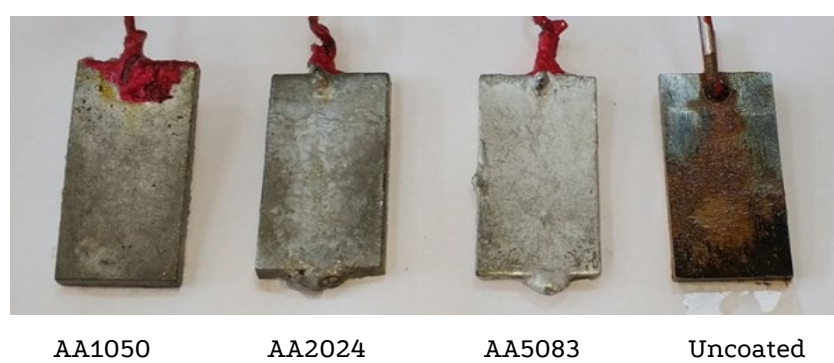

Figure 4. Surfaces of samples after immersion test
Table 4. Weight changes of samples after corrosion test and corrosion penetration rates

\begin{tabular}{ccccc}
\hline & Before & After & $\begin{array}{c}\text { Weight (g) } \\
\text { Difference }\end{array}$ & CPR (mm/year) \\
\hline Uncoated & 40.9804 & 40.4744 & 0.5060 & 0.6807 \\
AA1050 coated & 44.8270 & 44.8050 & 0.0220 & 0.0824 \\
AA2024 coated & 47.1629 & 46.9337 & 0.2292 & 0.8589 \\
AA5083 coated & 47.2767 & 47.2731 & 0.0036 & 0.0148 \\
\hline
\end{tabular}

\subsection{Oxidation Test Results}

Figure 5 shows the weight changes during the oxidation process of the structural steels covered with AA1050, AA2024, and AA5083 alloys. When compared to the coated steels, it is seen that the highest weight increase occurs in steels coated with AA2024. When compared with the average increase of AA1050 and AA5083, it is seen that the weight increase of AA1050 coated steel is approximately $0.74 \mathrm{mg} / \mathrm{cm}^{2}$ in the first ten hours, and the increase continues a little gradually in the following hours. In steel coated with AA5083, it is seen that the weight increases in the first hour is approximately $0.78 \mathrm{mg} / \mathrm{cm}^{2}$, and the increase continues in a near-constant in the following hours [14]. This result has shown that the AA5083 coatings can be used in environments where high oxidation resistance is desired. The weight change of uncoated St37 at the end of the oxidation process reached about $40 \mathrm{mg} / \mathrm{cm}^{2}$. The weight change of St37 was approximately 35 times more than that of the coated parts.

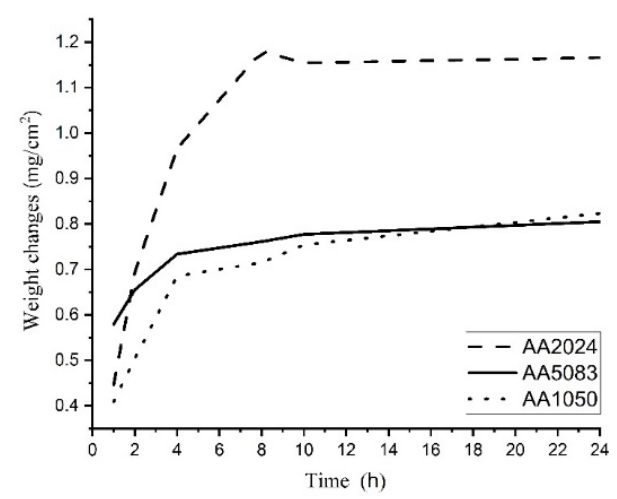

Figure 5. Weight changes of AA1050, AA2024 and AA5083 coated samples

The surface images of the coated and uncoated samples after the oxidation process are shown in figure 6 . While a thick scale layer was observed on the surface of the uncoated steel surfaces, no significant degradation occurred on the coated surfaces coated. Oxidation product, $\mathrm{Al}_{2} \mathrm{O}_{3}$, is so protective and avoids oxidation growth. 


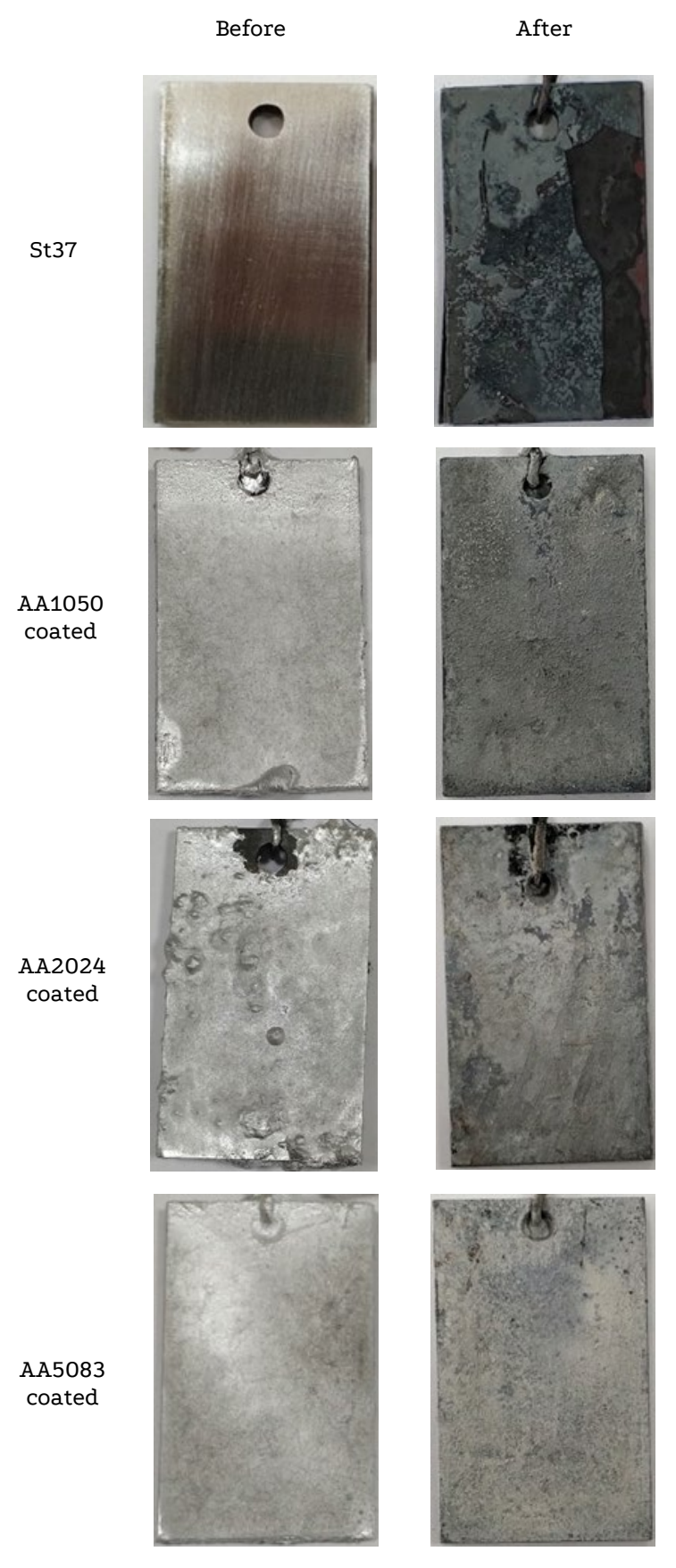

Figure 6. Optical photos of the uncoated and coated sample surfaces after oxidation test

\section{Conclusion}

The aluminum coatings were successfully deposited on the only mechanically cleaned steel substrate. At the end of the hot dip process, the samples taken out of the aluminum melt were cooled by water immediately. Cooling in the water took a few seconds and then continued at room temperature. Limiting the water-cooling process to a few seconds and then cooling in the air environment further improved the adhesion of the coating and allowed the diffusion of the intermetallic layer to be formed into the steel comfortably throughout the cooling process. In this way, it was inhibited detaching of the aluminum in the upper layer from the steel surface during cooling due to different thermal expansions. As a result of the cross-sectional examination of the coatings, it was observed that two different structures were formed, consisting of an aluminum coating on the upper surface and an intermetallic layer of $\mathrm{Fe}-\mathrm{Al}$ at the interface. As a result of XRD analysis, it was determined that the intermetallic layer structure consists of Fe2Al5 and FeAl3 phases. The EDS analysis showed that the intermetallic layer was predominantly composed of Fe2Al5 in the samples coated with AA1050 and AA5083, and FeAl3 in the samples coated with AA2024. Immersion corrosion study shows that the AA5083 alloy coatings exhibit a superior corrosion resistance in the chloride environment compared to AA1050 and AA2024 due to the presence of magnesium in the coating. AA5083 coated steels can be used in marine environments, and thereby corrosion losses can be decreased. The weight gain because of high temperature oxidation of the uncoated samples was approximately 33 times greater than the coated samples. The weight gain of steel samples coated with the AA5083 series was lower than all other samples. This suggests that AA5083 coatings can be used where high temperature oxidation resistance is required.

\section{Acknowledgments}

Authors thanks Dr. Taha Cagri Senocak and Ataturk University-The Coordination Unit of Scientific Research Projects for providing financial support for this study (within the scope of the project, numbered FYL-2018-6503).

\section{Declaration of Conflict of Interests}

The authors declares that there is no conflict of interest. They have no known competing financial interests or personal relationships that could have appeared to influence the work reported in this paper.

\section{References}

[1.] Tracton, A.A., Coatings materials and surface coatings. CRC Press, USA (2006)

[2.] Takata, N., Nishimoto, M., Kobayashi, S. and Takeyama, M., Crystallography of Fe2Al5 phase at the interface between solid Fe and liquid Al. Intermetallics 67 (2015) 1-11.

[3.] Liu, R., An Overview of Aluminum Protective Coating Properties and Treatments. OPTI, The University of Arizona (2009) 8.

[4.] Deqing, W., Ziyuan, S., Effect of Ceramic Particles on Cell Size and Wall Thickness of Aluminum Foam. Materials Science and Engineering: A 361 (2003) 45-49.

[5.] Wang, C.J., Chen, S.M., Microstructure and cyclic oxidation behavior of hot dip aluminized coating on Ni-base superalloy Inconel 718. Surface and Coatings Technology 201(7) (2006) 3862-3866.

[6.] Davis, J.R., ASM Specialty Handbook: Aluminum and Aluminum Alloys. General Introduction, USA, ASM International (1993) 784.

[7.] Chang, Y.Y., Tsaur, C.C., Rock, J.C., Microstructure studies of an aluminide coating on $9 \mathrm{Cr}-1 \mathrm{Mo}$ steel during high temperature oxidation. Surface and Coatings Technology 200(22) (2006) 6588-6593.

[8.] Awan, G., Ahmed, F., Ali, L., Hasan, F., Shuja, M., Effect of coatingthickness on the formability of hot dip aluminized steel. Pakistan Journal of Engineering and Applied Sciences 2 (2008) 13-21.

[9.] Awan, G.H., Ul Hasan, F., The morphology of coating/substrate interface in hot-dip-aluminized steels. Materials Science and Engineering: A 472(1-2) (2008) 157-165.

[10.] Su, C.W., Lee, J.W., Wang, C.S., Chao, C.G., Liu, T.F., The effect of hot-dipped aluminum coatings on Fe-8Al-30Mn-0.8C alloy. Surface and Coatings Technology 202(9) (2008) 1847-1852. 
[11.] Huilgol, P., Bhat, S., Bhat, K.U., Hot-Dip Aluminizing of Low Carbon Steel Using Al-7Si-2Cu Alloy Baths. Journal of Coatings (2013) 6.

[12.] ETI Aluminium Corp., Alüminyum ve Alüminyum Alaşımlarının Kimyasal Bileşimleri. Retrieved, http://www.etialuminyum.com/ (2019).

[13.] Trueba, M., Trasatti, S.P., Study of Al alloy corrosion in neutral $\mathrm{NaCl}$ by the pitting scan technique. Materials Chemistry and Physics 121(3) (2010) 523-533.

[14.] Van Alboom, A., Lemmens, B., Breitbach, B., De Grave, E., Cottenier, S., Verbeken, K., (2017). Multi-method identification and characterization of the intermetallic surface layers of hotdip Al-coated steel: FeAl3 or Fe4Al13 and Fe2Al5 or Fe2Al5+x. Surface and Coatings Technology 324 (2017) 419-428.

\section{How to Cite This Article}

Ezirmik, K.V., Kalan, F., Corrosion and High Temperature Oxidation Behavior of Structural Steels Coated with Aluminum Alloys, Brilliant Engineering, 3(2021), 22-26.

https://doi.org/10.36937/ben.2021.003.005 